\title{
Aviation Living Learning Community: Impacts on Student Success
}

\author{
Nicholas Wilson, Elizabeth Bjerke, and Leslie Martin \\ University of North Dakota
}

\begin{abstract}
The purpose of this study was to examine the impact on student academic success and retention while participating in an aviation-themed living learning community on a college campus. The data for this study was drawn from 625 new students (freshman and transfer) who enrolled at the University with an aviation major declared at the start of the 2012 and 2013 fall semesters. The study compared the difference in academic performance and retention between students $(\mathrm{N}=82)$ living in the Aviation Living Learning Community (ALLC) against those not living in the ALLC. The study found significant differences between the two groups of students in Fall GPA and academic grade in the Private Pilot ground school, students participating in the ALLC did significantly better than their peers not living in the ALLC. There was no significance found between the two groups in regards to retention at the University, or staying in the aviation program.
\end{abstract}

\section{Introduction}

Higher education has been under increasing pressure from the general public, lawmakers, and even the President of the United States to bring student outcomes and accountability for those outcomes to the forefront of the debate on the quality of higher education. In a December 2014 article in the Chronicle of Higher Education, the author outlined the initial plan of the current Administration to quantify student success (Field). Metrics which are proposed to be included within this program include, but may not be limited to, average net price of the institution, completion rate, labor market outcomes (readiness for employment and salary), and loan repayment rates. The purpose of this program is to determine a standardized method to rank like-caliber colleges and universities and increase transparency for prospective students and parents who are about to embark on the journey of higher education (or funding of said journey). This program has been under development for over a year (Field, 2014) and brings with it both skepticism and increased scrutiny from those who may, at some point in the not-so-distant future, have to abide by its tenets.

As an alternative to the President's plan, some of the nation's respected higher education institutions have collaborated and created their own higher education metric called the Student Achievement Measure (Mangan, 2013). The obvious benefit of this alternative is that it originates within the organizations for which it is intended to govern, which should lead to increased buy-in from participating institutions as well as incorporating the expertise of professionals dedicated to improving student success metrics 
on a daily basis. Both options have the same end-goal in mind, but exercising parallel paths in pursuing the end-goal.

Academic programs in higher education have seen an increasing pressure to ensure student success from various levels of authority from the federal government down to the University or college level. With the pressure to increase accountability and improve various performance metrics such as increasing student retention and graduation rates, academic departments are implementing various high impact practices. Kuh (2008) identifies 10 high-impact practices such as first-year seminars, internships, service learning and learning communities that have been widely tested and proven successful in colleges around the nation.

Within the context of student success, the researchers involved in this study sought to quantify student success on a micro-scale with the desire of using this information to enhance the higher education experience and observed success metrics, retention and academic performance. The format employed was a grouping of students living together with the same chosen academic field of Aviation, commonly referred to as a Living Learning Community (LLC). A Living Learning Community can be further defined as a place where students both live and gather and where direct or auxiliary instruction of academic material takes place. Additionally both formal and informal career and academic advising by faculty and departmental staff is typically considered to be a core component of many Living Learning Communities. Many variations exist on how exactly living learning communities are structured and which student populations are involved.

\section{Institutional Profile}

Specifically examined in this study are the first-year student participants in the Aviation Living Learning Community (ALLC) living in an on-campus residence hall located at a public four-year institution. The ALLC is a partnership between the Department of Aviation and campus Residence Life. The institution reported a Fall 2014 total student enrollment of 14,906 of which 11,537 are undergraduate students and approximately $17.4 \%$ of these students live in University-provided residence halls (University of North

Dakota Division of University \& Public Affairs, 2014). Aviation student enrollment numbers are broken down by major in the table below. 
Table 1

Aviation Student Enrollment by Major.

\begin{tabular}{ll}
\hline Major / Term & Fall 2014 \\
\hline Air Traffic Control & 226 \\
Airport Management & 50 \\
Aviation Management & 111 \\
Aviation Tech. Management & 10 \\
Commercial Aviation & 865 \\
Flight Education & 31 \\
Unmanned Aircraft Systems & 154 \\
Total Undergraduate & 1447 \\
\hline
\end{tabular}

Researchers involved in this study sought to determine whether a difference exists between student participants in the ALLC and their academic performance and persistence within the declared program of study compared to non-participant peers at the University. Although numerous research has been performed on Living Learning Communities and their impact on student success, the authors were not able to locate any previous research related to aviation-themed residential living communities on university campuses.

\section{Review of the Literature}

During an analysis of literature involving LLCs and related subtopics of student persistence and academic success, several important themes were noted as they relate to this study. As presented in Tinto's (1993) Model of Student Departure and associated with the question of retention addressed in this study, six characteristics predict likelihood of student premature departure from selected four-year institution, including: pre-entry attributes, initial goals and commitments, institutional experiences, integration, goals and commitments over time and departure decision/outcome. Tinto's (1993) reference to Institutional Experiences highlights the partnership between the Academic and Social System which the Living Learning Community concept is specifically designed to address.

Living Learning Communities and studies related to their impact on student success and retention have been occurring for over five decades. The theory suggests that a strong linkage between the academic department and student life aspects of a post-secondary education have a direct correlation to student success. According to Inkelas, Vogt, Longerbeam, Owen, \& Johnson (2006) “...students in [Living Learning] programs are more likely to persist, exhibit stronger academic achievement, interact with faculty, and engage in a more intellectual residence hall atmosphere than students in traditional residence halls." (p. 41) This theory has been tested in a variety of universal and "themed" residential learning communities including, but not limited to engineering (Shushok \& Sriram, 2010), psychology (Grills, Fingerhut, Thadani, \& Machon, 2012), and $1^{\text {st }}$ year student leadership focused communities (Stewart, 2008). 
To illustrate the importance of linked academic and social environment, Grills et al (2012) stated:

As students are able to nurture student-student relationships and connections to a disciplinary interest and faculty associated with that discipline, they grow socially and intellectually. Subsequently, students' commitments to their undergraduate institution, their chosen major, and career trajectory are strengthened. (p. 44)

Specific attributes of the Psychology Early Awareness Program (PEAP) noted in the article include highly integrated learning environments where students take specifically identified courses as a cohort, are admitted earlier into residence halls as compared to nonPEAP participants, and participate in monthly "fireside chats" or socials with Psychology faculty members. (Grills et al, 2012)

Similarities and differences exist between the LLC literature reviewed and the structure and administration of the studied ALLC. Similarities include ALLC subjects being provided with uniquely designed programming opportunities both aviation-related as well as social and "live-well" (overall health improvement) presentations by residence hall staff. Additionally, particpants are invited to monthly or semi-monthly faculty socials which are typically informal, but are provided for the purpose of enhancing academic and/or career-related discussion and mentorship. ALLC participants are also provided with more focused academic advising with faculty and staff on-site support. This process occurs prior to enrollment in the spring and fall semesters.

Although certain similarities exist between the studied ALLC and those referenced in the literature review, there exist several differences. ALLC participants are not currently offered uniquely designed courses or take courses exclusively as a cohort, however this opportunity may be introduced in subsequent years. ALLC participants currently selfselect which is a common trait with selected other studies (Grills et al, 2012) however, this differs from what is practiced with the College Park Scholars Program at the University of Maryland where students are uniquely invited into the program based on academic achievement and prior high school involvement (Stewart, 2008). The present state of the ALLC program also differs from the College Park Scholars Program with respect to the level of infrastructure integration accomplished as a part of the initial preparation. Stewart (2008) notes, "Resident faciltities renovated the first floor of a vacant high-rise to accommodate classrooms, faculty, and administration office space. Floors 2 through 8 were painted; bathrooms and lounges were updated." (p. 52). At the initiation of the ALLC, no infrastructure modifications (other than cosmetic additions) were made to change the way the students live and integrate their learning expereience within the ALLC. Addition of classrooms or dedicated faculty offices could be one area for future consideration as the ALLC program advances at the University. 
Table 2

Attributes of Living Learning Communities

\begin{tabular}{lc}
\hline \multicolumn{1}{c}{ Attributes of Living Learning Communities Found in the } & $\begin{array}{c}\text { ALLC Attributes } \\
\text { Literature }\end{array}$ \\
\hline Self-Selection into LLC & $\mathrm{X}$ \\
Monthly Programing & $\mathrm{X}$ \\
Partnership between Student Affairs and Academic & $\mathrm{X}$ \\
Department & $\mathrm{X}$ \\
Participation from Faculty & \\
Embedded Faculty (office space) & \\
Designated Physical Space for Classes & \\
Courses Linked to LLC & \\
Early Admission to Halls & \\
\hline
\end{tabular}

Note. Table data consolidated from reviewed literature; Brower \& Inkelas, 2010; Grills, Fingerhut, Thadani, \& Machon, 2012; Stewart, 2008; Shushok \& Sriram, 2010.

As can be identified above, one of the more interesting aspects noted in the literature review was the high degree of variation on administrative responsibility and integration between the Academic Department and the partnering Residence Life unit of the University. This fact was specifically noted as it relates to the ALLC and how improvements and modifications may be realized in subsequent years.

Research regarding living learning communities has been widely published over the years, however the authors failed to find any literature exploring specific aviation-themed living learning communities during their search. This study serves to add to the body of knowledge in regards to living learning communities by examining academic success and retention data in relation to participation on an aviation-themed living learning community and answers the following research questions:

1) Is there is a difference in academic success between students participating in the aviation living learning community versus students not participating?

2) Is there a difference in retention both at the University as well as in the aviation program between students participating in the aviation living learning community versus students not participating?

\section{Methodology}

\section{Setting}

This study was conducted at a public, four-year, research university. As was noted earlier, during the Fall of 2014 there were nearly 15,000 students enrolled in over 200 fields of study at the University. On average, there are nearly 3,000 new students enrolled each fall semester. New students include both new freshman as well as new transfer students to 
the University. The Department of Aviation offers five aviation specific majors, and accounts for over $10 \%$ of the undergraduate population at the University.

During the Fall of 2012, the Department of Aviation partnered with Residence Life to offer the first aviation-themed living learning community at the University. The first year was limited to one wing of a residence hall with 35 available slots, the second year it doubled consisting of an entire floor of the residence hall. Only new students to the University, with a declared interest in aviation were permitted access to live in the ALLC during their first year on campus. The resident assistants (RAs) in the LLC were aviation majors, and the Department of Aviation worked closely with Residence Life to provide various programs to the residents.

\section{Participants}

Two cohorts of students comprise the sample for this study. Each cohort consists of new students (freshman and transfer) enrolled as aviation majors at the University. One cohort began in the Fall of 2012, while the other began on the Fall of 2013. Students participating in the aviation living learning community were identified allowing for comparison analysis. Much of the literature in regards to first year student success focuses solely on new freshman data. However, since both new freshman and new transfer students were allowed to live in the ALLC, this research will include both for analysis.

\section{Data Collection}

The data used in this study was obtained from existing academic records through the University's Office of Institutional Research (OIR). Students participating in the ALLC were identified in the data set. This study uses a quantitative approach to compare student success and persistence between students participating in the ALLC and those not participating.

Student success is measured by term grade point average (GPA), credit hours passed and academic grade in the Introduction to Aviation course which is commonly referred to as Private Pilot ground school. Student persistence is measured by enrolling in the subsequent fall semester. Persistence is subsequently broken down by both remaining at the University as well as remaining an aviation major. The single independent variable in this study relates to participating in the ALLC.

\section{Procedures}

The original dataset was obtained from the Office of Institutional Research as a detailed Excel file. Once the data was sorted and coded, it was uploaded into the Statistical Package for Social Science (SPSS) version 20. Part-time students and students entering into the University as non-aviation majors were deleted from the dataset. For the purposes of 
answering the research questions, both descriptive and inferential statistics were used. The significance for this study was set at the .05 level.

\section{Results}

The sample for this study consisted of two cohorts of students entering into the University during the Fall of 2012 and the Fall of 2013. Both new freshman and new transfer students were included in the analysis of data, as both types of new students participated in the ALLC. The following tables provide descriptive analysis of the dataset in its entirety, followed by the comparison between students participating in the ALLC and those not participating.

Table 3

Descriptive Analysis of Dataset $(N=625)$

\begin{tabular}{lll}
\hline Characteristics & $\mathrm{N}$ & $\%$ \\
\hline Year Enter & & \\
$\quad$ Fall 2012 & 351 & 56.2 \\
$\quad$ Fall 2013 & 274 & 43.8 \\
Admit Type & & \\
$\quad$ New Freshman & 486 & 77.8 \\
$\quad 139$ & 22.2 \\
$\quad$ New Transfer & & 13.1 \\
Participation & 82 & 86.9 \\
$\quad$ Aviation Living Learning Community & 543 & \\
$\quad$ Non-ALLC &
\end{tabular}

In this study student success is defined by a variety of metrics. First, student credit hours passed and failed was used as a measure of degree completeness. A student at this particular university requires 125 credit hours to graduate, thus the more credit hours completed successfully, versus credits failed, would lead to greater degree completions at a faster rate. Term GPA was also included as a success measure. Lastly, since this living learning community was focused in the aviation department, an analysis of academic performance during the Private Pilot ground school was also included, the score is based on a typical 4.0 grading scale. Table 4 lists the descriptive analysis of the various success variables. 
Table 4

Descriptive Analysis of Success Variables

\begin{tabular}{lccc} 
Success Variable & Mean & Standard deviation & $\begin{array}{c}\text { Sample size } \\
(\mathrm{n})\end{array}$ \\
\hline Student Credit Hours & & & \\
$\quad$ Fall Credit Pass & & & 625 \\
Fall Credit Fail & 11.55 & 3.53 & 625 \\
Spring Credit Pass & 0.75 & 2.11 & 598 \\
Spring Credit Fail & 11.70 & 4.43 & 598 \\
& 0.73 & 2.04 & \\
Term Grade Point Average & & & 625 \\
$\quad$ Fall GPA & 3.01 & 0.86 & 598 \\
Spring GPA & 2.81 & 1.00 & \\
& & & 413 \\
Academic Course Grade & & & \\
$\quad$ Private Pilot Ground School & 2.65 & 1.29 & \\
\end{tabular}

Student retention in this study was defined two ways: retention at the University and retention within the aviation program. The overall retention rate at the University between the first and second year for the aviation students identified was $86 \%$, indicating that 537 of the 625 students remained enrolled at the University after the first year. This is significantly higher than the University's overall retention rate which is typically maintained near $75 \%$. It is important to note that of the 625 students who initially came into the University as an aviation major, $77 \%$ or 481 students remained as an aviation student at the University after the first year

This study aimed to answer two defined research questions in regards to the impact of participating in an ALLC on the success of students during their first year at the University. The first research question sought to see if there was a significant difference in academic success between students participating in the ALLC and non-participants. Success was measured through seven different dependent variables: fall credits passed, fall credits failed, spring credits passed, spring credits failed, Fall GPA, Spring GPA and grade in Private Pilot ground school. Of the seven variables, four proved to be significantly different. Table 4 displays the results of the t-test analysis for the seven variables. (University of North Dakota Division of University \& Public Affairs, 2014) (OIR) 
Table 5

t-test Analysis of Success Variables for ALLC and non-ALLC

\begin{tabular}{|c|c|c|c|c|c|}
\hline & \multicolumn{2}{|c|}{ ALLC Participation } & \multirow[b]{2}{*}{$t$} & \multirow[b]{2}{*}{$d f$} \\
\hline & & ALLC & Non-ALLC & & \\
\hline Fall Credits Passed & & $\begin{array}{l}12.23 \\
(1.78)\end{array}$ & $\begin{array}{l}11.44 \\
(3.57)\end{array}$ & 1.89 & 623 \\
\hline Fall Credits Failed & & $\begin{array}{l}0.27 \\
(1.09)\end{array}$ & $\begin{array}{l}0.82 \\
(2.22)\end{array}$ & $-2.20 *$ & 623 \\
\hline Spring Credits Passed & & $\begin{array}{l}12.75 \\
(4.29)\end{array}$ & $\begin{array}{l}11.54 \\
(4.44)\end{array}$ & $2.26^{*}$ & 596 \\
\hline Spring Credits Failed & & $\begin{array}{l}0.81 \\
(2.84)\end{array}$ & $\begin{array}{l}0.71 \\
(1.89)\end{array}$ & 0.39 & 596 \\
\hline Fall GPA & & $\begin{array}{l}3.17 \\
(0.70)\end{array}$ & $\begin{array}{l}2.99 \\
(0.88)\end{array}$ & $2.03 *$ & 623 \\
\hline Spring GPA & & $\begin{array}{l}2.96 \\
(0.94)\end{array}$ & $\begin{array}{l}2.79 \\
(1.01)\end{array}$ & 1.44 & 596 \\
\hline $\begin{array}{l}\text { Grade Private Pilot } \\
\text { School }\end{array}$ & Ground & $\begin{array}{l}2.97 \\
(1.07)\end{array}$ & $\begin{array}{l}2.59 \\
(1.32)\end{array}$ & $2.19 *$ & 411 \\
\hline
\end{tabular}

Note. ${ }^{*} \mathrm{p}<.05$. Standard Deviations appear in parenthesis below means

The second research question aimed to identify if there was a difference in retention rates between students participating in the aviation living learning community compared to students not participating. For this analysis, a chi-square test was chosen due to the nature of the variables. Although no significance was found, Table 6 and 7 depict the results in regards to university retention and aviation major retention respectively.

Table 6

Chi-Square of ALLC participation and university retention $(N=625)$

\begin{tabular}{llll}
\hline & \multicolumn{3}{c}{ ALLC Participation } \\
\cline { 2 - 3 } & ALLC & Non-ALLC & $\chi 2$ \\
\hline Yes (Observed/Expected) & $72 / 70.6$ & $46 / 466.4$ & 0.240 \\
No (Observed/Expected) & $10 / 11.4$ & $78 / 76.6$ & \\
\hline
\end{tabular}


Table 7

Chi-Square of ALLC participation and aviation major retention $(N=625)$

\begin{tabular}{llll}
\hline & \multicolumn{3}{c}{ ALLC Participation } \\
\cline { 2 - 3 } & ALLC & Non-ALLC & $\chi^{2}$ \\
\hline Yes (Observed/Expected) & $67 / 63.1$ & $414 / 417.9$ & 1.20 \\
No (Observed/Expected) & $15 / 18.9$ & $129 / 125.1$ & \\
\hline
\end{tabular}

\section{Discussion and Recommendations}

The two research questions analyzed centered around two student metrics, academic success and retention rates. The findings of this study correlate to previous research (Grills et al., 2012) which saw an increase in GPAs from students participating in living learning communities. Departments, colleges and universities are concerned about retaining students from year to year so further examination into possible retention techniques is necessary.

\section{Academic Success}

Students participating in the ALLC had a significantly higher GPA their first semester on campus, versus those that did not participate in the ALLC. Also, the number of attempted and failed fall credits were significantly less for those students participating in the ALLC. These results could be attributed to the tutoring available on the ALLC. Various faculty and airport staff visited the wing once or twice a semester to specifically cover Aviation course content. For the past two years the RAs have held weekly study sessions, "Homework Mondays" and "Sunday Afternoon Study Sessions" to name few examples of ALLC facilitated study.

Another contributing factor to these results is that the students are integrated within a floor with multiple other students and RAs of the same or similar aviation majors. If the students have questions they can simply leave their room and ask an RA or another student for help. When selecting a suitable RA, the Department of Aviation was involved in selecting a student who would serve as a positive role model for the new students entering the program. One of biggest criterion for the department was that the potential RA had successfully completed the Introduction to Aviation Private Pilot ground school and subsequent flight training.

The specific grade in the Private Pilot ground school was also found to be significantly higher for those students living in the ALLC. The Private Pilot ground school is a typical freshman course and could be taken fall or spring or summer semester. Again, since the students participating in this LLC were all freshmen or transfer students a high number of them would be in the course at the same time. Study groups were easily formed on the floor or in their community. Faculty and staff that work with students within the Private 
Pilot ground school also attended scheduled monthly socials similar to what the Department of Psychology did with their PEAP LLC study (Grills et al, 2012), as well as attending various study sessions held on the community.

The amount of credits completed successfully during the Spring semester was also significantly higher for those students who live on the LLC. The study habits and techniques learned from the Fall semester may have created an environment which fostered learning therefore students knew what to expect from their second semester at college. The various study sessions continued into the Spring semester as well as monthly visits from faculty and staff. The interaction with the faculty and staff may also have increased the comfort level of students asking questions if they needed help. Research has shown that student-faculty interactions have been proven to promote integration of students into the academic life of the University (Garrett \& Zabriskie, 2003) .

\section{Student Retention}

Historically, the Department of Aviation within the University has a higher retention rate than the rest of the University averaging around 80\%, (University of North Dakota Division of University \& Public Affairs, 2014) The researchers wanted to determine if there was a significant difference in retaining students at a higher rate if they were a part of the ALLC. The data did not show that the ALLC had any significance in retaining students within the University. Although the data did not show significance, the percentage of students retained from the ALLC did prove to be $88 \%$ as compared to $86 \%$ from students that were not a part of the ALLC. Through compiling the data the researchers did note that although small numbers, there were some transfer students on the ALLC. Further research opportunity exists to research retention of transfer students participating in the ALLC as compared to transfer students not participating in the ALLC.

\section{Recommendations}

Brower and Inkelas (2010) stated that successful LLCs need to have clear learning objectives with an academic focus. To address the pre-requisite relationship for a successful program, the ALLC was created with mutual desire between the University Residence Life and the Department of Aviation. Both of these campus stakeholders thought it would be a great addition to the University's experience for a select number of aviation students. The University's ALLC had very informal goals that have been verbally communicated, but nothing has been formally documented or advertised. Verbal feedback from the RAs has indicated that participation in wing/floor/hall planned events has been declining. Over the years, the Department of Aviation has changed the focusing of programs from more formal monthly dinners, to hosting socials in the ALLC residence hall. This has subsequently increased participation. This improved participation could be partially attributed to the student mix this semester, the hall staff involved, or the convenience of the exchange with faculty on the wing versus at a secondary location. Researchers propose that establishing clear goals and communicating said goals will serve 
to improve the efficacy of the ALLC experience and the overall academic success and retention of those participating.

\section{Coordination}

Referenced in the PEAP study (Grills et al, 2012, p.47), Brower and Inkelas (2010) also stated that another characteristic of a successful LLC was for the program to have a strong relationship between the academics and student affairs components. Various LLCs have faculty that live within the community (Shushok \& Sriram, 2010), however the current ALLC environment is not presently equipped to handle this option. Although current university faculty do not live on the floor, they are still involved in routine interactions with ALLC students. ALLC faculty liaisons have bi-weekly meetings with the RAs and Resident Life Coordinator. These meetings are designed to discuss programming ideas, existing upcoming programs, and in general to see how student life on the wing is proceeding. These meetings are a great way to communicate, however faculty have noted that the same or similar discussion topics have taken place from year one to year three. For example, if a collaborative program was very successful one year, then the organizational information should be kept and used for the following year.

\section{Selection process}

During the formation of the ALLC at the University, the Department of Aviation was asked which student populations should be included as participants in the ALLC. It was decided that the focus should be on new students to the University (freshman or transfer). When students receive their acceptance letter to the University they receive their housing application and on the application is an option to select that you are an aviation major and that you would be interested in living on the ALLC. The applications are collected and students are selected to live on the ALLC on a first come first serve basis. The only exception is for female students. As aviation is a male-dominated career field and the ALLC is embedded within a co-ed hall, the likelihood of a gender imbalance exists due to the majority of potential candidates being male. To address this, Residential Life offered some degree of preference to female applicants into the ALLC to facilitate a gender distribution which more closely reflects the remainder of the residence hall.

As it pertains to program growth, the first year of the ALLC there was one suite of four beds for females and it filled. The other 31 beds on the community were occupied by male students. The second year the ALLC was expanded to an entire floor of 70 beds. A little less than half the rooms were held with the intent that female students would request to live on the floor. The rooms were soon released to male students as there were only enough female responses to fill one suite (of four) again in addition to the female RA. Now in year three there are two suites of female students ( 8 total with 62 male students) and a female RA. 
As growth has been witnessed in the ALLC program, researchers propose more formal selection processes be established for participants. Researchers believe that implementing moderate, not overly arduous, entrance requirements will improve the experience for students who have expressed more formal commitment to the mission of the ALLC. The logic is that a certain degree of personal ownership is required, for example, to write a one page essay indicating your interest in ALLC participation and how it may impact your university experience. Although researchers did not uncover specific research which supports this proposed condition, it is worth investigating in the interest of program refinement.

\section{Limitations of this Study}

Researchers note certain limitations associated with the ALLC study. The first of these limitations was the small sample size of the ALLC population. Although the community has been growing steadily from 35 residents the first year of its existence in the Fall of 2012 to 70 residence starting the Fall of 2014 (note: no data was collected or reported on for Fall 2014 participants due to the timing of this study) addition to the sample size (N) will serve to validate findings listed previously in this study. To facilitate this statistical preference, the ALLC participants may be paired in the future with the three other Living Learning Communities on campus, being Honors, Engineering and Wellness, however it should be noted that this may not serve the end-goal of focusing specifically on aviation students' retention and academic performance.

The second limitation of the study is the admission process of ALLC participants. Presently there is no entrance requirement or additional process required of ALLC participants as students are admitted into the program. ALLC participants "self-select" into the program without respect for their prior academic performance, extracurricular participation, or level of commitment to the degree program. The positive attribute to this approach is that the impact of the ALLC on the residence may be less based on their degreecommitment and prior experience and more on the exposure they receive while receiving specialized programs and exposure to faculty interaction not typically witnessed by nonALLC participants. The potential negative to this approach as that the ALLC as a whole may not be as academically committed or accomplished as would a group more specifically recruited for participation. The side-effect may include a larger variation in commitment coming into the program and students not taking full advantage of the additional resources being afforded to them.

\section{Conclusion}

Researchers in this study were able to show the relationship between participation in the Aviation Living Learning Community and student success. Of the variables selected

for testing student success, four returned results which indicated a statistically significant difference which can be used to explain the association between participation in the ALLC and positive student academic outcomes. These variables included a lower number of fall 
semester credits failed, an increased number of spring credits passed, fall semester GPA and the final grade in the Private Pilot ground school. In addition to student success, the researchers also sought to determine whether participation in the ALLC led to higher retention within the degree program, however no statistically significant differences were noted in the data.

Although more research is needed, the researchers believe that several factors contribute to the findings summarized above. Some of these proposed factors include increased student-faculty interaction, living amongst like-minded peers with similar career aspirations, and specialized programming opportunities tailored to the academic programs. Although this list is not all encompassing, the researchers believe these factors are the most influential towards contributing to student academic success. As for additional opportunity to enhance the student experience and impact of the ALLC, the researchers propose determining clear goals for the ALLC with Residence Life partners and communicating these goals to students, staff and faculty advisors as has proven successful in other themed-LLCs. Finally, researchers propose a modified selection program for student participants in the LLC. Although currently students come on a first-come, firstserved basis, the researchers believe a judicious process for selecting academicallycommitted and goal-oriented aviation students will further enhance the impact to the entire ALLC as a whole and create environment where living and learning is truly exemplified. 


\section{References}

Brower, A. M., \& Inkelas, K. K. (2010). Living Learning Programs - One High Impact Educational Practice We Now Know a Lot About. Liberal Education, 36-43.

Field, K. (2014, December 19). Obama's College-Ratings Plan Arrives, but Most Specifics Stay Behind. The Chronicle of Higher Education.

Garrett, M. D., \& Zabriskie, M. S. (2003). The Influence of Living-Learning Program Participation on Student-Faculty Interaction. The Journal of College and University Student Housing, 38-44.

Grills, C. N., Fingerhut, A. W., Thadani, V., \& Machon, R. A. (2012). Residential Learning Communities Centered with a Discipline: The Psychology Early Awareness Program. New Directions for Teaching and Learning, 43-55.

Inkelas, K. K., Vogt, K. E., Longerbeam, S. D., Owen, J., \& Johnson, D. (2006). Measuring Outcomes of Living-Learning Programs: Examining College Environments and Student Learning and Development. JGE: The Journal Of General Education, 4076.

Kuh, G. D. (2008). High-Impact Educational Practices: What They Are, Who Has Access to Them, and Why They Matter. Washington, DC: AAC\&U.

Mangan, K. (2013, June 13). Higher-Ed Groups Unveil Alternative to Federal StudentSuccess Measures. The Chronicle of Higher Education.

Office of Institutional Research (OIR). (n.d.). Grand Forks, ND: University of North Dakota.

Shushok, F., \& Sriram, R. (2010). Exploring the Effect of A Residential Academic AffairsStudent Affairs Partnership: The First Year of an Engineering and Computer Science Living-Learning Center. The Journal of College and University Student Housing, 68-78.

Stewart, G. M. (2008). Assessing Learning Outcomes in Living-Learning Programs: One Journey. The Journal of College and University Student Housing, 50-65.

Tinto, V. (1993). Leaving College: Rethinking the Causes and Cures of Student Attrition.

University of North Dakota Division of University \& Public Affairs. (2014, November). UND Student Body Profile 2014-2015. Retrieved from http://und.edu/discover/student-profile/index.cfm 